\title{
A EDUCAÇÃO PATRIMONIAL NA AVALIAÇÃO DE IMPACTO AMBIENTAL: POSSIBILIDADES DE APLICAÇÃO DE UMA PERSPECTIVA DE ARQUEOLOGIA PÚBLICA
}

\section{A U T O R}

MsC. Tatiana Costa Fernandes

tatiana@preservararqueologia.com.br

Dr. Laercio Loiola Brochier

laercio.brochier@ufpr.br
PRESERVAR Arqueologia e Patrimônio

Universidade Federal do Paraná - UFPR

\section{R E S U M O}

O artigo reflete sobre o uso da perspectiva da Arqueologia Pública em uma atividade de Educação Não-Formal realizada no Projeto de Salvamento Arqueológico do Sítio Topo do Guararema, localizado no Vale do Paraíba em São Paulo. O trabalho foi pensado a partir da abordagem da Apresentação e Interpretação Pública da ciência arqueológica visando contribuir para os aspectos educacionais, auto-afirmação e conhecimento da história précolonial da região.

Palavras-chave: Arqueologia Pública, Educação Patrimonial, Avaliação de Impacto Ambiental.

O panorama atual da Gestão de Recursos Arqueológicos (GRA) no Brasil vem se caracterizando por um aumento significativo das demandas pela pesquisa arqueológica em todo o país fruto, em sua maior parte, das pressões exercidas pelos ideais desenvolvimentistas e conservacionistas. Se por um lado, os anseios da sociedade pelo crescimento econômico têm levado a uma verdadeira "ebulição" de empreendimentos pelo território nacional, por outro, surgem apelos científicos e públicos para que estas mudanças não tragam consigo, a destruição de valores apropriados e reapropriados por esta mesma sociedade. Questões como desenvolvimento sustentável, conservação da biodiversidade, educação ambiental ou sócio-ambiental, gestão participativa, entre outros, confrontam com as metas de crescimento da sociedade, e obviamente com os interesses de grupos específicos.

O avanço da temática ambiental e arqueológica reforça ainda mais o papel dos arqueólogos ligados à GRA nos processos de planejamento da Nação, considerando que estes sempre foram e serão processos políticos (PLOG, 1978: 422).

Neste sentido, a Arqueologia e as Ciências de modo geral têm revisto sua posição e sua agenda social diante da fragmentação das fronteiras entre as nações, obrigando as mesmas a uma 'redefinição' da questão da cultura, sociedade e etnicidade, sendo vital que se coloque a diversidade histórica e cultural e o reconhecimento do outro, como metas na formação dos indivíduos enquanto cidadãos (GOHN, 2005, SILVA \& GRUPIONI, 2004). A perspectiva de valoração da diversidade histórica e cultural propiciaria eliminar muito dos preconceitos para com outras culturas e estabelecer bases para um entendimento mais amplo do futuro da sociedade através do 
exercício da cidadania (WALDMAN, 2003; RIBEIRO, 2003; SILVA \& GRUPIONI, 2004, NEVES, 2004).

Por sua vez, as Ciências vêm buscando também superar as barreiras da especialização das disciplinas e das divisões do saber e produzir uma ciência unificada da sociedade (SPRIGGS, 1983:3 apud FUNARI, 1998:9) focada, sobretudo, na cooperação multidisciplinar e nas possibilidades de diálogo entre os especialistas e a sociedade. A Arqueologia também se insere nesta perspectiva, refletindo sobre "a impossibilidade de desentranhar a pesquisa dos interesses sociais", na medida que os próprios estudiosos "são o produto da cultura e suas interpretações do passado são influenciadas pelo meio cultural" (FUNARI, 1998 ).

A preocupação com a "apresentação" da Arqueologia para o público vem proporcionando diálogos cada vez mais profícuos com outras ciências e saberes, como, a Educação, a Museologia e a Comunicação Social. No entanto, a necessidade de pensar em formas apropriadas de comunicação com foco na interdisciplinaridade e na transversalidade tornou a Educação uma questão pública essencial na Arqueologia.

Nas décadas de 1980 e 1990 nos Estados Unidos, novos direcionamentos teóricos enfatizaram aspectos políticos e públicos da Arqueologia (JAMESON, 2004). As reflexões no campo da Arqueologia Pública, principalmente em relação à interdisciplinaridade entre Arqueologia e Educação, foram debatidas no World Archaeological Congress (1986), O evento trouxe para o debate teórico a abordagem chamada de Arqueologia Mundial, que visa entender não somente como as pessoas viveram no passado, mas também como e por que mudanças acabaram resultando nas formas de sociedade e cultura existentes na atualidade (UCKO, 1994:1).

Do ponto de vista dessas abordagens, o interesse social da Arqueologia é ultrapassar o caráter estático, sem implicações para o contexto histórico e social, direcionando-se conjuntamente a outras disciplinas humanas e sociais, para uma análise desse contexto em toda a sua dimensão, dentro de um processo contínuo onde o homem é sujeito ativo, o qual pode mudar e transformar a sua dinâmica de ininterrupta produção da realidade social (ZAMORA, 1990). Os pressupostos discutidos nessas linhas teóricas reforçam o papel social da Arqueologia e estabelecem assim a abertura necessária para o diálogo com outros profissionais, bem como, com grupos sociais interessados no patrimônio arqueológico e suas interpretações.

Sobre as relações entre Arqueologia e Educação, a publicação de Stone \& McKenzie (1994) traz a discussão sobre questões do passado que são excluídas do ensino formal, demonstrando como a pré-história e grupos tradicionais são vistos pelos currículos escolares. Na Europa, assim como em outros continentes, o início da história se dá a partir da 'civilização', ou seja, reproduzindo a história enquanto imagem de 'progresso' privilegiando a visão de determinados grupos dominantes em detrimento dos povos 'não civilizados'. Conforme os autores, o perigo real do ponto de vista educacional é que as crianças estão sendo induzidas ao desprezo pelo passado pré-histórico, visto como um período de tecnologia simples, e consequentemente por qualquer sociedade não industrializada. As três principais problemáticas levantadas com respeito à dificuldade de acesso dos estudantes ao passado, em várias partes, estão relacionadas principalmente ao currículo, o despreparo dos professores e a falta de material didático 
adequado (STONE \& MCKENZIE et al, 1994:2).

Trabalhos de Arqueologia Pública nos Estados Unidos têm constatado ausências de conhecimento do passado no presente e avaliado sua importância para as gerações atuais e futuras. A partir disso, esforços acadêmicos e profissionais buscam desenvolver uma base valorativa com envolvimento na Educação e, ao mesmo tempo, cultivar um discernimento em relação à herança cultural da Nação (JAMESON, 1997).

Diante disso, a Arqueologia Pública vem colaborando com historiadores, museólogos, curadores e outros especialistas em bens e referências culturais, na elaboração de estratégias para transmitir o valor da Arqueologia. Como consequência, programas interpretativos e educacionais destinados à sociedade foram desenvolvidos, cujo processo deu-se em conjunto com a organização e coordenação de simpósios acadêmicos, workshops e sessões de treinamento nos Estados Unidos e em outros países para a troca de idéias entre os diversos profissionais (JAMESON, 1997).

UmaespecialidadenestalinhacompreendeaabordagemdaApresentação e Interpretação Pública da informação arqueológica, envolvendo desde a Educação Formal e a elaboração de currículo até programas, como visitas a sítios e exposições museológicas. O termo também abrange estratégias específicas de comunicação, tais como: publicação de histórias populares, cartazes e folders de conscientização pública e criação de apresentações de multimídia incluindo a rápida proliferação desses recursos por meio da internet (JAMESON, 1997). Adotam-se ainda, programas de Educação Não-Formal (outreach), como tentativas sistemáticas de fornecer serviços educacionais, além das formas convencionais de Educação. A Interpretação Pública também engloba estratégias de comunicação entre arqueólogos e não especialistas como, por exemplo, monitores de parques, cujo trabalho é transmitir a "mensagem" da Arqueologia a uma gama variada de públicos. Os especialistas e profissionais que coordenam essas atividades incluem arqueólogos, historiadores, interpretes (on-site interpreters), professores, escritores, artistas, curadores, museólogos e outros especialistas.

Embora ligada à ciência arqueológica, a Interpretação Pública difere do escopo de discussões técnico-acadêmicas que visam exclusivamente interpretações e inferências sobre o passado, pois tem como foco a tradução de conceitos e informações arqueológicas e sua comunicação simultânea a um público amplo. Assim, a Interpretação Pública preocupa-se com o engajamento, entretenimento e informação de uma maneira eticamente consciente (JAMESON, 1997).

Por sua vez, não há como dissociar o valor científico da disciplina com o seu valor público. A Arqueologia provê benefícios não somente para a pesquisa arqueológica profissional, mas também para muitos participantes e públicos que a utilizam e a valorizam (LITTLE, 2002). Como ressalta Little, "os benefícios públicos estende-se para além da pesquisa arqueológica, utilizando sítios e artefatos para propostas tais como: educação, coesão (autoafirmação) comunitária, entretenimento e desenvolvimento econômico" (LITTLE, 2002:3). 
No contexto da Arqueologia brasileira ligada a Gestão de Recursos Arqueológicos a Educação Patrimonial é delineada através das políticas públicas estabelecidas pela legislação arqueológica. A Portaria IPHAN 07/1988 prevê a realização de ações educativas no contexto de projetos de Arqueologia de salvamento. Por sua vez, a Portaria IPHAN 230/2002 define como política pública a exigência do desenvolvimento da Educação Patrimonial nos projetos de Arqueologia ligados ao Licenciamento Ambiental de empreendimentos geradores de impacto ao patrimônio arqueológico. A Educação Patrimonial caracterizada pelo IPHAN pode então ser entendida como uma denominação genérica utilizada para caracterizar a Educação Não-Formal no contexto do patrimônio cultural, incluindo o arqueológico.

Conforme Brandão (2005:9) não há, uma única forma nem um único modelo de Educação, e a escola também não é o único lugar onde ela acontece e talvez nem seja o melhor; o ensino escolar não é a sua única prática e o professor profissional não é o seu único praticante. Neste cenário, observa-se uma ampliação do conceito de Educação, que não se restringe mais aos processos de ensino-aprendizagem no interior de unidades escolares formais, transpondo os muros da escola para os espaços da casa, do trabalho, do lazer, do associativismo (GOHN, 2005). Com isto a Educação reestrutura-se reformulando o campo da Educação Não-Formal, a qual aborda processos educativos que ocorrem fora das escolas, em processos organizativos da sociedade civil, ao redor de ações coletivas do chamado terceiro setor da sociedade, abrangendo movimentos sociais e organizações não-governamentais (GOHN, 2005, BRANDÃO, 2005). Também englobaria ainda outras entidades e instituições como museus, parques e empresas de consultoria em Arqueologia (ações educativas), etc.

Assim, a Educação Não-Formal realizada no contexto da Avaliação de Impacto Ambiental se caracteriza como uma possibilidade de contribuição da Arqueologia para a Sociedade, transmitindo o conhecimento gerado pelas pesquisas. Entretanto, à pesquisa arqueológica realizada neste contexto possui delimitações impostas entre outros, pelo cronograma (tempo); recursos financeiros; os tipos de empreendimentos e suas especificidades técnicas; dificuldade ou impossibilidade de retorno à área, entre outros (CALDARELLI, 1999-2000:59).

Deste modo, para a elaboração de programas e ações educativas no âmbito Não Formal, verifica-se igualmente a necessidade de uma avaliação abrangente e integrada dos aspectos condicionadores da pesquisa científica e dos elementos que irão auxiliar a demarcação da forma e abrangência dessas ações, tendo em conta os seguintes componentes gerais: características do empreendimento e suas peculiaridades técnicas, espaciais e temporais; as informações sobre contextos locais e regionais (ambiental, arqueológico, etno-histórico, etc.) e a planificação (design) da pesquisa; as comunidades afetadas e os públicos potenciais.

Ao integrar as discussões e contextos sobre as abordagens de Interpretação Pública e as possibilidades da Educação Não-Formal nas propostas de Gestão de Recursos Arqueológicos, o Programa de Educação Patrimonial realizado no Salvamento do Sítio Arqueológico Topo do Guararema (SCIENTIA, 2004), constituiu estudo de caso pertinente na 
aplicação desta abordagem.

O programa foi estruturado com base na avaliação das características do empreendimento, design da pesquisa e comunidades (público potencial). Deste modo, foram consideradas as peculiaridades técnicas da montagem de torres de linha de transmissão (500 KV); o cronograma físico da obra (fase de instalação e operação); o contexto informacional do sítio (relacionado às problemáticas arqueológicas e etno-históricas); os vestígios e estruturas identificadas; a planificação da pesquisa (metodologia e técnica de evidenciação da cultura material remanescente); cronograma físico da pesquisa e da ação educativa, bem como, inserção das comunidades e públicos envolvidos. A partir dessas considerações foram caracterizados os atributos ou elementos de significância a serem avaliados (Quadro 1), compondo os aspectos científicos e públicos do sítio e do projeto. A elaboração da ação educativa privilegiou as possibilidades de uso das informações materializadas do passado (vestígios, estruturas e ecofatos), das práticas do método científico da Arqueologia e, da percepção sobre a importância do conhecimento arqueológico para a Educação, para a

valorização do patrimônio cultural e desenvolvimento cultural humano. Quadro 1 - Atributos ou elementos de significação utilizados na avaliação do projeto e do sítio Topo do Guararema com consequências para a elaboração da proposta de Educação Não-Formal.

\section{Elementos / Significâncias}

- Problemática arqueológica e etno-histórica regional;

- Metodologia de escavação empregada (superfície ampla - decapagem e níveis artificiais);

- Grau de preservação das estruturas e vestígios materiais identificados e expostos;

- Variabilidade de vestígios constituídos de conjuntos e estruturas material lítico (polido e lascado), material cerâmico (fragmentos e peças inteiras), material ósseo (restos faunísticos), estruturas de combustão (restos de antigas fogueiras) e uma laje de argila queimada (possível área de atividade de produção e queima de vasilhames cerâmicos);

- Quantidade e qualidade de vestígios e estruturas localizadas. No total, foram localizadas e resgatadas mais 25 mil peças entre material lítico e material cerâmico, além de material ósseo. Foram, também, evidenciadas 17 estruturas de combustão e uma laje de argila queimada;

- Outras significâncias com correspondência pública - significância histórica (remetendo ao período específico da ocupação do município) e significância étnica (único exemplar de sítio indígena localizado no município, remetendo a ocupação indígena descrita na etno-história regional).

- Extensão da área escavada (aproximadamente 2.000 m2) e técnica de escavação empregada;

- Potencial de perceptibilidade (visibilidade) dos vestígios e estruturas arqueológicas;

- Implantação e aspectos de inserção na paisagem;

- Ocorrência, evidenciação e possibilidade de permanência de estruturas in situ;

- Único sítio arqueológico localizado e escavado no município;

- O número de pessoas envolvidas nos trabalhos de campo (aproximadamente 43 pessoas, sendo 10 profissionais, entre arqueólogos e estagiários e 33 auxiliares de campo). Este número de auxiliares variou durante o período de realização dos trabalhos, no entanto este número não chegou a ser inferior a dez;

- Todos os auxiliares são moradores do município de Guararema;

- Proximidade da área urbana (facilidade de acesso).

A avaliação dos atributos de significância científica e pública elencados no contexto do projeto demonstrou alto potencial de utilização do sítio nas atividades destinadas à Educação Não-Formal. Esta perspectiva direcionou 
o programa para a Apresentação e Interpretação Pública, a partir do contato com o sítio arqueológico no momento de sua escavação e com a exposição das evidências materializadas do passado no presente.

A atividade desenvolvida baseou-se em uma abordagem construtivista, conforme COPELAND (2004). O autor desenvolveu um esquema sobre os principais fatores e processos envolvidos na construção de significados pelo público, através da apresentação e interpretação em um sítio arqueológico "in situ", conforme Figura 1. Diante da experiência proporcionada pela evidência arqueológica, inicia-se um processo contínuo de construção de significados, por meio da organização de novos dados, transformação de idéias, formação ou modificação de conceito. A comunicação realizada possibilita a ponte entre a construção do especialista e a construção do público, onde o indivíduo incorpora informação ao selecionar aspectos que Ihe são significantes.

O programa implantado no sitio Topo do Guararema foi dividido em três fases contendo as seguintes ações: 1) abordagem de apresentação e interpretação pública de forma oportunística durante o curso da escavação arqueológica; 2) "O sítio em exposição" - abordagem de apresentação e interpretação pública realizada de forma sistemática durante cinco dias; 3) Oficina Preservacionista - capacitação com enfoque conservacionista

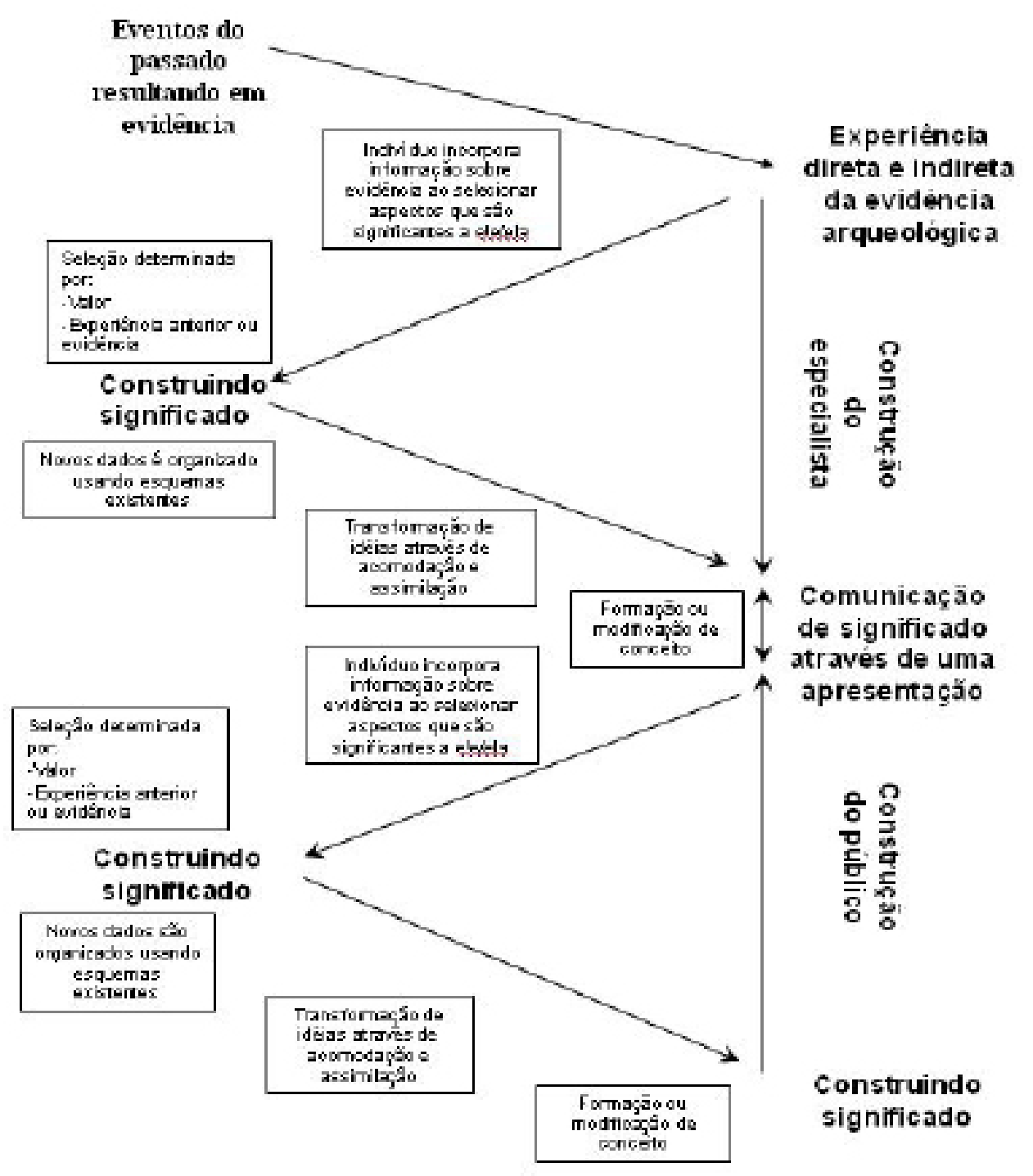

Figura 1: Esquema sobre os principais fatores e processos envolvidos na construção de significados pelo público em um sitio arqueológico. Fonte: Copeland (2004), traduzido. e na responsabilidade do uso do conhecimento arqueológico (formação de possíveis técnicos).

Ao considerar os elementos ou atributos de significância, o programa foi direcionado para dois públicos. O primeiro referese aos auxiliares de campo, contratados para serviços gerais, envolvidos nas atividades de escavação (limpeza do terreno, peneiramento e rebaixamento das camadas arqueológicas com acompanhamento técnico). Este grupo foi constituído em sua maioria por homens, de faixas etárias variadas entre 18 e 50 anos, habitantes da área rural e urbana do município de Guararema. Com pouco ou nenhum conhecimento sobre Arqueologia, seu interesse recaiu inicialmente na relação de prestação de serviços, sem envolvimento com questões de patrimônio cultural. Posteriormente, houve um processo de assimilação e valorização importante, seja ao longo dos 4,5 meses de resgate arqueológico, e notadamente 
quando da participação desses auxiliares na fase de apresentação do sitio em exposição.

O segundo público escolhido compreendeu professores e estudantes do Ensino Fundamental e Médio do Sistema Público de Ensino municipal crianças e adolescentes de 11 a 19 anos (em média), em fase de formação educacional formal e cidadã. $O$ interesse deste grupo recaiu nos benefícios educacionais da Arqueologia, no desenvolvimento cultural humano e nas questões envolvidas com o patrimônio cultural do município, vislumbrados durante a visitação ao sítio arqueológico. A ação denominada "Sítio em exposição" foi realizada em 5 dias, com 24 turmas de duas escolas públicas localizadas na área urbana do município de Guararema - envolvendo turmas de $5^{\circ}$ e $7^{\circ}$ séries do ensino fundamental, $1^{\circ}, 2^{\circ}$ ano do ensino médio e $3^{\circ}$ ano do magistério.

Para a estruturação do "O Sítio em Exposição" foram elaboradas

\section{O S ÍTIO E M EXPOS I ÇÃO}

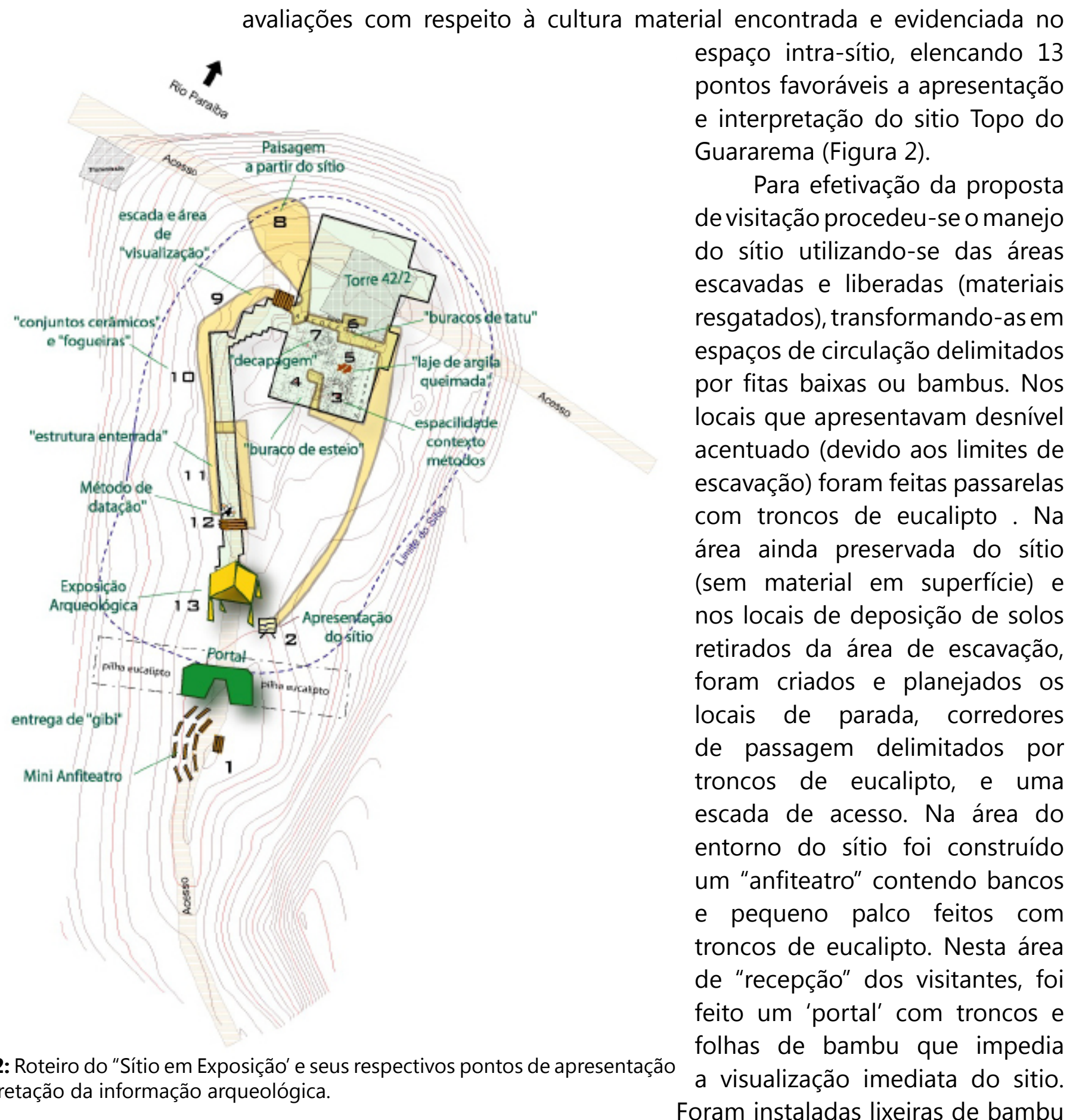

Figura 2: Roteiro do "Sítio em Exposição' e seus respectivos pontos de apresentação e interpretação da informação arqueológica.

Foram instaladas lixeiras de bambu 
ao longo de todo o percurso.

Conforme a abordagem construtivista proposta, cada ponto de apresentação possibilitou diferentes experiências e possibilidades interpretativas (Quadro 2), onde primeiramente houve um processo de construção do especialista a partir da inferência arqueológica, e posteriormente, a interpretação pública enquanto incorporação de informações, transformação de ideias, seleção de aspectos significativos e modificação de conceitos.

Quadro 2 - Roteiro da proposta do "Sítio em exposição" - Pontos de apresentação das informações arqueológicas

\begin{tabular}{|c|c|c|c|}
\hline Pontos & $\begin{array}{l}\text { Interpretação } \\
\text { arqueológica }\end{array}$ & Apresentação & $\begin{array}{c}\text { Estratégias de } \\
\text { Interpretação Pública }\end{array}$ \\
\hline $\begin{array}{l}\text { Circuito } \\
\text { de entrada } \\
\text { e retorno } \\
\text { (acesso) }\end{array}$ & $\begin{array}{l}\text { - Percepção da área de entorno } \\
\text { do sítio, em caminho que } \\
\text { percorre o sopé de morro, a } \\
\text { média e alta encosta; Aspectos } \\
\text { da área de implantação do } \\
\text { sítio arqueológico (escolhido } \\
\text { pelo grupo que o construiu e } \\
\text { o habitou). }\end{array}$ & $\begin{array}{l}\text { - Primeiro contato com o lugar e } \\
\text { suas referências atuais (conhecido } \\
\text { por uns; desconhecido por } \\
\text { outros); } \\
\text { - Os visitantes são recepcionados } \\
\text { pelos monitores, que os } \\
\text { conduzem ao sítio. } \\
\text { - Osmonitoressãoimediatamente } \\
\text { reconhecidos pelos visitantes } \\
\text { (pois são moradores da cidade); }\end{array}$ & $\begin{array}{l}\text { - Aproveitamento do acesso } \\
\text { e suas dificuldades de subida, } \\
\text { como elemento de discussão } \\
\text { sobre estratégias de implantação } \\
\text { do sítio; }\end{array}$ \\
\hline $\begin{array}{c}1 \text { Ponto: } \\
\text { Recepção } \\
\text { (anfiteatro }\end{array}$ & $\begin{array}{l}\text { - Área no limite do sítio } \\
\text { arqueológico; } \\
\text { - Introdução a temática da } \\
\text { cultura material (vestígios) } \\
\text { e Arqueologia; significados } \\
\text { e importância dos sítios } \\
\text { arqueológicos; } \\
\text { - orientações sobre as } \\
\text { fragilidades dos vestígios } \\
\text { materiais, o cuidado com as } \\
\text { áreas de escavação, questão } \\
\text { do lixo e das áreas de } \\
\text { passagem e monitores; }\end{array}$ & $\begin{array}{l}\text { - Proporcionar o primeiro } \\
\text { contato com os arqueólogos e } \\
\text { com o ambiente do sítio; } \\
\text { - Criação de um ambiente } \\
\text { receptivo, direcionado para a } \\
\text { motivação da curiosidade e de } \\
\text { expectativas quanto à visita ao } \\
\text { sítio arqueológico; } \\
\text { - Motivação através de } \\
\text { questionamento dos estudantes } \\
\text { sobre informações do passado } \\
\text { de Guararema, seu ambiente e } \\
\text { habitantes iniciais; } \\
\text { - Manipulação de cultura } \\
\text { material do passado (fragmentos } \\
\text { cerâmicos e líticos); }\end{array}$ & $\begin{array}{l}\text { - Fornecer conceitos básicos para } \\
\text { possibilitar a interpretação; } \\
\text { - Proporcionar elementos de } \\
\text { correlação entre o contexto } \\
\text { histórico de ocupação do } \\
\text { município com os pressupostos e } \\
\text { objetivos da Arqueologia; } \\
\text { - Rememorar informações obtidas } \\
\text { anteriormente sobre evidências } \\
\text { arqueológicas encontradas e } \\
\text { informações arqueológicas; }\end{array}$ \\
\hline $\begin{array}{l}2 \text { Ponto: } \\
\text { Apresentação } \\
\text { do sítio e do } \\
\text { projeto }\end{array}$ & $\begin{array}{l}\text { - Área no limite entre a área } \\
\text { escavada e preservada do sí- } \\
\text { tio; } \\
\text { - Visibilidade espacial da área; } \\
\text { - Contexto da pesquisa arque- } \\
\text { ológica (gestão de recursos } \\
\text { arqueológicos no Brasil - exi- } \\
\text { gências legais); }\end{array}$ & $\begin{array}{l}\text { - Contexto dos estudos arqueo- } \\
\text { lógicos desenvolvidos no licen- } \\
\text { ciamento ambiental empreendi- } \\
\text { mentos; } \\
\text { - Contextos específicos e etapas } \\
\text { do trabalho da LT Tijuco Preto - } \\
\text { Cachoeira Paulista (enfatizando } \\
\text { as etapas realizadas pelos arque- } \\
\text { ólogos - diagnóstico, prospec- } \\
\text { ção, monitoramento, delimitação } \\
\text { e resgate); }\end{array}$ & $\begin{array}{l}\text { - Proporcionar conhecimento so- } \\
\text { bre os aspectos legais relaciona- } \\
\text { dos ao patrimônio arqueológico; } \\
\text { - Utilização da torre já instalada } \\
\text { como elemento comparativo do } \\
\text { impacto realizado que poderia ser } \\
\text { feito no sítio arqueológico. }\end{array}$ \\
\hline
\end{tabular}




\begin{tabular}{|c|c|c|c|}
\hline Pontos & $\begin{array}{l}\text { Interpretação } \\
\text { arqueológica }\end{array}$ & Apresentação & $\begin{array}{c}\text { Estratégias de } \\
\text { Interpretação Pública }\end{array}$ \\
\hline $\begin{array}{l}3 \text { Ponto: } \\
\text { Espacialidade, } \\
\text { Contexto e } \\
\text { Método }\end{array}$ & $\begin{array}{l}\text { - Área de atividade associada } \\
\text { a área de refugo contendo } \\
\text { estruturas de fogueiras } \\
\text { (duas), associadas a conjuntos } \\
\text { cerâmicos fragmentados } \\
\text { sobre uma estrutura; } \\
\text { - Área de refugo (descarte) } \\
\text { com grande quantidade } \\
\text { de fragmentos cerâmicos e } \\
\text { lítios esparsos por toda área, } \\
\text { associado a manchas de solo } \\
\text { com colorações escuras; }\end{array}$ & 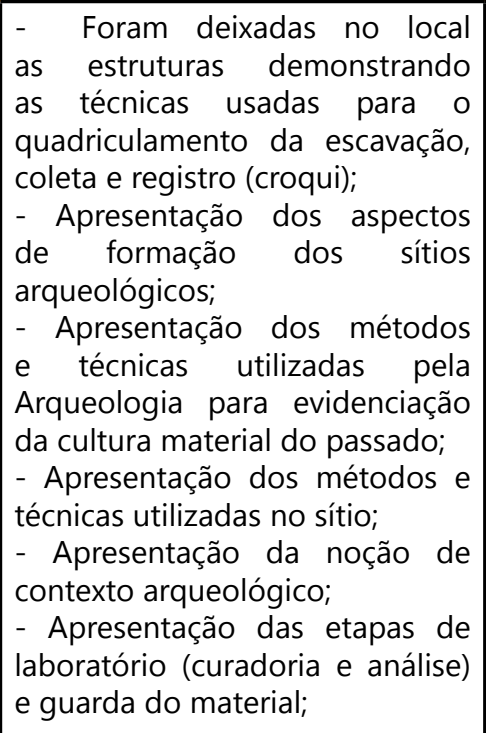 & $\begin{array}{l}\text { - Proporcionar subsídios básicos } \\
\text { para a interpretação das evidência } \\
\text { e áreas intra-sítio; } \\
\text { - Proporcionar de correlações } \\
\text { entre o conhecimento escolar } \\
\text { (disciplinas) e do senso } \\
\text { comum,com método científico } \\
\text { utilizado pela Arqueologia; } \\
\text { - Propiciar reflexão sobre o sítio e } \\
\text { seu significado como patrimônio } \\
\text { cultural da população de } \\
\text { Guararema; ara destinação do } \\
\text { - Instigar sobre a dés as } \\
\text { material arqueológico após } \\
\text { etapas de pesquisa; }\end{array}$ \\
\hline $\begin{array}{l}4 \text { Ponto: } \\
\text { "Buraco de } \\
\text { Esteio" }\end{array}$ & $\begin{array}{l}\text { - Área localizada no limite } \\
\text { entre área de atividade e } \\
\text { área habitacional contendo } \\
\text { evidência de buraco de esteio; }\end{array}$ & $\begin{array}{l}\text { - Apresentação de outras } \\
\text { evidencias materiais, inclusive } \\
\text { indiretas; } \\
\text { - Apresentação da técnica de } \\
\text { escavação para verificação } \\
\text { da evidências sobre espaços } \\
\text { específicos no sítio e sua função; } \\
\text { - Noção de área de atividade; }\end{array}$ & $\begin{array}{l}\text { - Aproveitamento das evidências } \\
\text { indiretas (manchas no solo) para } \\
\text { a interpretação das estruturas de } \\
\text { casas construídas no passado; } \\
\text { - Situar as evidências em } \\
\text { contextos mais amplos no interior } \\
\text { do sítio, a fim de gerar inferências } \\
\text { mais confiáveis; }\end{array}$ \\
\hline $\begin{array}{l}5 \text { Ponto: } \\
\text { "Laje de argila } \\
\text { queimada" }\end{array}$ & $\begin{array}{l}\text { - Área contendo evidencia } \\
\text { de laje produzida com argila } \\
\text { contendo bolotas de argila e } \\
\text { fragmentos cerâmicos entre } \\
\text { e sobre a estrutura (possível } \\
\text { área de produção e queima de } \\
\text { vasilhames cerâmicos) }\end{array}$ & $\begin{array}{l}\text { - Apresentação de outras } \\
\text { evidencias materiais,inclusive } \\
\text { indiretas; } \\
\text { - Noção de possível área de } \\
\text { atividade comunitária no espaço } \\
\text { do sítio; }\end{array}$ & $\begin{array}{l}\text { - Aproveitamento da evidencia } \\
\text { para a interpretação de aspectos } \\
\text { do conhecimento tecnológico } \\
\text { na produção de cerâmica e no } \\
\text { cotidiano do passado; }\end{array}$ \\
\hline $\begin{array}{l}6 \text { Ponto: } \\
\text { "Buracos de } \\
\text { tatu" }\end{array}$ & $\begin{array}{l}\text { - Área contendo evidências } \\
\text { de bioturbações (buracos } \\
\text { produzidos por animais ou } \\
\text { plantas) }\end{array}$ & $\begin{array}{l}\text { - Apresentação da noção de } \\
\text { dinâmica, sistêmica de sítio } \\
\text { arqueológico; } \\
\text { - Apresentação de evidência } \\
\text { que podem gerar problemas } \\
\text { interpretativos das camadas } \\
\text { arqueológicas; }\end{array}$ & $\begin{array}{l}\text { - A necessidade de registro e } \\
\text { controle das características dos } \\
\text { solos e dos terrenos, e seu uso } \\
\text { atual; }\end{array}$ \\
\hline $\begin{array}{l}7 \text { Ponto: } \\
\text { "Decapagem" }\end{array}$ & $\begin{array}{l}\text { - Área contendo fragmentos } \\
\text { cerâmicos expostos (em } \\
\text { processo de escavação) } \\
\text { associados a estrutura de } \\
\text { combustão próxima a área de } \\
\text { habitação; }\end{array}$ & $\begin{array}{l}\text { - Apresentação de uma das } \\
\text { técnicas de escavação usadas } \\
\text { no sítio (rebaixamento discreto e } \\
\text { decapagem); }\end{array}$ & $\begin{array}{l}\text { - Alusão às dificuldades e } \\
\text { possibilidades expostas pela } \\
\text { técnica de escavação; } \\
\text { - Utilização de monitores } \\
\text { locais nas explicações e praticas } \\
\text { realizadas in loco durante a } \\
\text { visitação; }\end{array}$ \\
\hline $\begin{array}{l}8 \text { Ponto: } \\
\text { "Paisagem do } \\
\text { sítio" }\end{array}$ & $\begin{array}{l}\text { - Área fora do limite da } \\
\text { escavação (encosta de maior } \\
\text { declive voltada para o rio } \\
\text { Paraíba) }\end{array}$ & $\begin{array}{l}\text { - Apresentação dos aspectos da } \\
\text { paisagem do entorno do sítio; } \\
\text { - Visualização do rio Paraíba do } \\
\text { sul e sua distância do sítio }\end{array}$ & $\begin{array}{l}\text { - Aproveitamento dos aspectos } \\
\text { ambientais e paisagísticos do } \\
\text { entorno como elemento de } \\
\text { discussão sobre estratégias de } \\
\text { implantação do sítio; }\end{array}$ \\
\hline $\begin{array}{l}9 \text { Ponto: } \\
\text { "visualização" }\end{array}$ & $\begin{array}{l}\text { - Área elevada formada por } \\
\text { resíduo de solo retirado da } \\
\text { área escavada; }\end{array}$ & $\begin{array}{l}\text { - Apresentação de outra técnica } \\
\text { de escavação utilizada no sítio } \\
\text { (níveis arbitrários de } 10 \mathrm{~cm} \text {, com } \\
\text { manutenção de conjuntos para } \\
\text { controle de nível arqueológico); } \\
\text { - Apresentação de cantos } \\
\text { indígenas aproveitando aspectos } \\
\text { perceptivos sobre a área do sitio } \\
\text { e paisagem circundante; }\end{array}$ & $\begin{array}{l}\text { - Possibilitar uma visualização } \\
\text { "êmica" do contexto sistêmico da } \\
\text { aldeia e seus habitantes. Inserção } \\
\text { de questões de gênero; atividades } \\
\text { no interior e exterior da aldeia; } \\
\text { antiga cobertura vegetal e a } \\
\text { captação de recursos.. }\end{array}$ \\
\hline
\end{tabular}




\begin{tabular}{|c|c|c|c|}
\hline Pontos & $\begin{array}{l}\text { Interpretação } \\
\text { arqueológica }\end{array}$ & Apresentação & $\begin{array}{c}\text { Estratégias de } \\
\text { Interpretação Pública }\end{array}$ \\
\hline $\begin{array}{l}10 \text { Ponto: } \\
\text { "conjunto } \\
\text { cerâmico e } \\
\text { fogueiras" }\end{array}$ & $\begin{array}{l}\text { - Área de atividade de } \\
\text { descarne de caça e preparação } \\
\text { de alimentos (evidência } \\
\text { de conjuntos cerâmicos } \\
\text { associados a restos faunísticos } \\
\text { (ósseo),material lítico e um } \\
\text { conjunto de quatro estruturas } \\
\text { de combustão); }\end{array}$ & $\begin{array}{l}\text { - Apresentação de mais uma } \\
\text { área de atividade; } \\
\text { - Apresentação de fragmentos } \\
\text { cerâmicos com diferentes } \\
\text { tamanhos e formas; } \\
\text { - Apresentação de evidências } \\
\text { não localizadas em outras áreas } \\
\text { intra-sítio. }\end{array}$ & $\begin{array}{l}\text { - Proporcionar a noção de } \\
\text { aproveitamento da aldeia para } \\
\text { realizar diferentes atividades } \\
\text { como em suas casas (local de } \\
\text { dormir, local de cozinhar, etc); } \\
\text { - Aproveitamento dos } \\
\text { fragmentos para correlações } \\
\text { entre os usos dos vasilhames e } \\
\text { sua forma e tamanho; }\end{array}$ \\
\hline $\begin{array}{l}11 \text { Ponto: } \\
\text { "estrutura } \\
\text { enterrada" }\end{array}$ & $\begin{array}{l}\text { - Área contendo estrutura } \\
\text { escavada associada } \\
\text { estrutura de combustão } \\
\text { camada orgânica enterrada; }\end{array}$ & $\begin{array}{l}\text { - Apresentação da noção de } \\
\text { estratigrafia arqueológica; } \\
\text { - Apresentação das hipóteses da } \\
\text { interpretação da evidência; } \\
\text { - Apresentação do tipo de } \\
\text { sítio arqueológico denominado } \\
\text { estrutura subterrânea e os } \\
\text { locais onde são geralmente } \\
\text { encontrados; }\end{array}$ & $\begin{array}{l}\text { - Aproveitamento da evidencia } \\
\text { para suscitar a noção de } \\
\text { ambigüidade e dúvida (incerteza) } \\
\text { em ciência; } \\
\text { - Necessidade de correlações } \\
\text { e verificações das evidencias } \\
\text { (afirmações empíricas) a fim de } \\
\text { gerar inferências, interpretação e } \\
\text { conhecimento; }\end{array}$ \\
\hline $\begin{array}{l}12 \text { Ponto: } \\
\text { "método de } \\
\text { datação" }\end{array}$ & $\begin{array}{l}\text { - Área localizada no final do } \\
\text { acesso contendo estrutura de } \\
\text { combustão isolada. }\end{array}$ & $\begin{array}{l}\text { - Apresentação do método de } \\
\text { datação por carbono } 14 . \\
\text { - Apresentação da quantidade } \\
\text { de coletas realizadas no sítio; } \\
\text { - Apresentação da forma de } \\
\text { coleta e cuidados necessários } \\
\text { (contaminação); } \\
\text {-Apresentação dos laboratórios } \\
\text { que realizam analise das } \\
\text { amostras; }\end{array}$ & $\begin{array}{l}\text { - Aproveitamento da evidencia } \\
\text { para aprofundar a discussão dos } \\
\text { conhecimentos sobre química, } \\
\text { biologia e ciências obtidos em } \\
\text { sala de aula } \\
\end{array}$ \\
\hline $\begin{array}{l}13 \text { Ponto: } \\
\text { "exposição } \\
\text { arqueológica" }\end{array}$ & $\begin{array}{l}\text { - Área localizada em trecho já } \\
\text { escavado no acesso inferior, } \\
\text { utilizado como espaço de } \\
\text { exposição; }\end{array}$ & $\begin{array}{l}\text { - Apresentação didática e } \\
\text { fotográfica da evolução do } \\
\text { processo de escavação do sítio; } \\
\text { - Apresentação na primeira } \\
\text { mesa: materiais arqueológicos } \\
\text { retirados do sítio e outros } \\
\text { materiais de outros sítios, com } \\
\text { figuras ilustrativas de como eles } \\
\text { foram fabricados e utilizados. } \\
\text { - Apresentação na segunda } \\
\text { mesa: figuras mostrando as } \\
\text { etapas da pesquisa arqueológica } \\
\text { (escavação e laboratório) e } \\
\text { materiais utilizados na pesquisa } \\
\text { (desde receptor GPS até pincéis). }\end{array}$ & $\begin{array}{l}\text { Aproveitamento dos artefatos } \\
\text { expostos na primeira mesa para } \\
\text { a reflexão do conhecimento } \\
\text { tecnológico das sociedades } \\
\text { indígenas em relação a matéria } \\
\text { prima, a fabricação dos artefatos } \\
\text { e seu uso cotidiano; } \\
\text { - Aproveitamento dos materiais } \\
\text { e figuras da segunda mesa para } \\
\text { o entendimento do trabalho do } \\
\text { arqueólogo; } \\
\text { - Propiciar reflexão sobre os } \\
\text { outros usos propiciados por } \\
\text { objetos conhecidos do cotidiano; } \\
\text { - Propiciar reflexão sobre os } \\
\text { conhecimentos escolares em } \\
\text { Geografia e outros materiais e os } \\
\text { materiais eletrônicos utilizados } \\
\text { por arqueólogos em seu } \\
\text { trabalho. } \\
\text { - Propiciar a noção da } \\
\text { interrelação entre a pesquisa } \\
\text { arqueológica e o significado da } \\
\text { exposição de materiais culturais } \\
\text { (como no caso de um museu } \\
\text { municipal); }\end{array}$ \\
\hline
\end{tabular}

A atividade também contou com a entrega de material impresso tipo gibi - contando a história de uma turma que visita um sítio arqueológico. A história foi elaborada com base na proposta realizada no Topo do Guararema, com personagens inspirados na equipe de campo (auxiliares, arqueólogos e estagiários). 


\section{CONSIDERAC Õ ES FINAIS}

As reflexões a presentadas nesta discussão e no estudo de caso envolvem a perspectiva da Arqueologia Pública enquanto campo de pesquisa voltado para as questões públicas e científicas. Este campo enseja a proteção e preservação do patrimônio arqueológico, a compreensão e valorização da informação arqueológica, e ainda, a defesa dos interesses profissionais, científicos e públicos da Arqueologia. Busca ainda desenvolver formas e instrumentos de diálogo direcionados a interceptação do trinômio CiênciaPatrimônio-Sociedade, onde a preservação, a ética, a gestão e a Educação constituem bases importantes para produção e acesso aos conhecimentos. Uma das propostas de Arqueologia Publica ressaltadas neste trabalho, compreende o potencial da perspectiva interpretativa-construtivista envolvendo o licenciamento ambiental de empreendimentos no Brasil. Este direcionamento implica no foco sobre abordagens vinculadas ao que se convencionou chamar de Educação Patrimonial, com a ampliação de suas ações no âmbito da Educação Não-Formal e respeitando as especificidades da ciência arqueológica. Assim, o processo comunicacional realizado em sitio arqueológico (on site) permite incorporar a experiência direta e indireta com a evidência arqueológica, gerando condições apropriadas para a construção de significados entre o especialista e o público, no âmbito da Gestão de Recursos Arqueológicos.

\section{A GRADECIMENTOS}

A Adriana Teixeira pelas discussões e revisão, a Manoel Ramos Junior pelo inventivo, a Solange Caldarelli pela oportunidade de desenvolver este trabalho, e aos profissionais, estagiários e auxiliares que participaram da pesquisa de campo no sitio Topo do Guararema. 


\section{B I B L I O G R A F I A}

COPELAND, T. Presenting archaeology to the public: constructing insights on-site. IN: MERRIMAN, Nick. Public Archaeology. London: Routledge, 2004. p. 132 - 144.

FUNARI, P. P. Arqueologia. São Paulo: Ática, 1988.

GOHN, Maria da Glória. Educação Não-Formal e Cultura Política: impactos sobre o associativismo do terceiro setor. 3 ed. São Paulo: Cortez, 2005.

JAMESON, J. H. Jr.Introduction: What this book is about. IN: JAMESON, J. H. Jr (ed). Presenting Archaeology to the public:digging for truths. London: Altamira Press, 1997. p. $11-20$.

JAMESON, J. H. Jr. Public archaeology in the United States. IN: MERRIMAN, Nick. Public Archaeology. London: Routledge, 2004. p. 21 - 58.

LIPE, W. Public Benefits of Archaeological Research. IN:LITTE, B (org). Public Benefits of Archaeology. University Press of Florida. 2002. 21-28.

LITTE, B. Archaeology as a Shared Vision. IN:LITTE, B (org). Public Benefits of Archaeology.University Press of Florida. 2002. 3-19.

NEVES, Eduardo Góes. Os índios antes de Cabral: arqueologia e história indígena no Brasil. IN:SILVA, Aracy Lopes da \& GRUPIONI, Luís Donisete Benzi (org). A Temática Indígena na Escola: novos subsídios para professores de $1^{\circ}$ e $2^{\circ}$ graus.4 ed. São Paulo: Global; Brasília: Mec: MARI: UNESCO, 2004. p. 171 - 192. PLOG, F. Cultural Resouce Management and The "New Archaeology". IN: REDMAN, C.L. et al. (ed.). Social Archaeology. Academic Press, 1978.

RIBEIRO, Wagner. Em busca da qualidade de vida. PINSKY, Jaime \& PINSKY, Carla Bassanezi. História da Cidadania. São Paulo: Contexto, 2003. 400-417.

SCIENTIA CONSULTORIA CIENTÍFICA. Projeto Resgate do Sítio Topo do Guararema, Município de Guararema, SP. São Paulo, 2004.

SILVA, Aracy Lopes da \& GRUPIONI, Luís Donisete Benzi. Introdução: Educação e Diversidade. IN:SILVA, Aracy Lopes da \& GRUPIONI, Luís Donisete Benzi (org). A Temática Indígena na Escola: novos subsídios para professores de $1^{\circ}$ e $2^{\circ}$ graus. 4 ed. São Paulo: Global; Brasília: Mec:MARI: UNESCO, 2004. p. 15 - 23. SPRIGGS, M.Another way of telling: Marxist perspectives. IN: SPRIGGS, M.(ed) Marxist perspectives in Archaeology. Cambridge, Cambridge University Press, p. 1 - 9. 1983.

STONE, Peter G. \&McKENZIE, Robert (eds). The excluded past : archaeology in education. London; New York :Routledge, 1994.

UCKO, P,.Museums and sites: cultures of the past within education Zimbabwe, some ten years on, in $\mathrm{P}$ STONE \&MOLYNEUX B (eds), The Presented Past: heritage, museums and education, 237-282. London: Routledge, 1994.

WALDMAN, Maurício. Natureza e Sociedade como espaço da Cidadania. PINSKY,Jaime \&PINSKY,CarlaBassanezi. História da Cidadania. São Paulo: Contexto, 2003. 545-561.

ZAMORA, Oscar M. Fonseca. A Arqueologia como História. Dédalo. São Paulo, n 28, p. 39 - 62, 1990. 